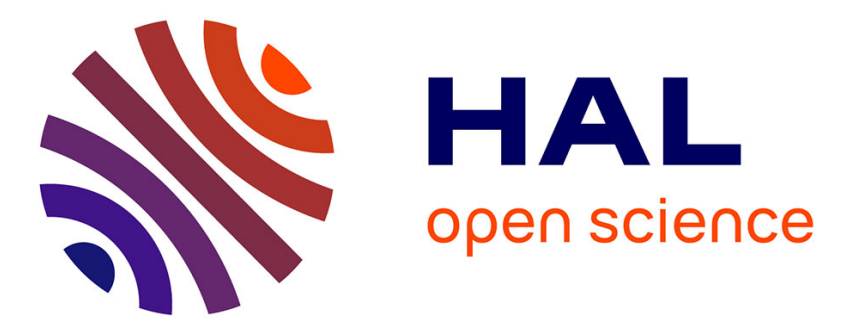

\title{
Stoichiometry and particle morphology effects on the aptitude to compaction of apatitic structure powders
}

\author{
Z. Hatim, Abderrahim Michrafy, M. Elassfouri, F. Abida
}

\section{To cite this version:}

Z. Hatim, Abderrahim Michrafy, M. Elassfouri, F. Abida. Stoichiometry and particle morphology effects on the aptitude to compaction of apatitic structure powders. Powder Technology, 2009, 190 (1-2, SI), pp.210-214. 10.1016/j.powtec.2008.04.040 . hal-01718078

\section{HAL Id: hal-01718078 \\ https://hal.science/hal-01718078}

Submitted on 7 Nov 2019

HAL is a multi-disciplinary open access archive for the deposit and dissemination of scientific research documents, whether they are published or not. The documents may come from teaching and research institutions in France or abroad, or from public or private research centers.
L'archive ouverte pluridisciplinaire HAL, est destinée au dépôt et à la diffusion de documents scientifiques de niveau recherche, publiés ou non, émanant des établissements d'enseignement et de recherche français ou étrangers, des laboratoires publics ou privés. 


\title{
Stoichiometry and particle morphology effects on the aptitude to compaction of apatitic structure powders
}

\author{
Z. Hatim ${ }^{\text {a, }}$, A. Michrafy ${ }^{\text {b,* }}$, M. Elassfouri ${ }^{\text {a }}$, F. Abida ${ }^{\text {a }}$ \\ ${ }^{a}$ Electrochimie et Biomatériaux, Faculté des Sciences, Université Chouaib Doukkali. B.P. 20, El Jadida, Morocco \\ ${ }^{\mathrm{b}}$ RAPSODEE, UMR 2392, Ecole des Mines d'Albi, campus Jarlard 81013 Albi cedex 09, France
}

\begin{abstract}
A B S T R A C T
Apatitic calcium phosphates powders with Ca/P molar ratio of 1.5 to 1.8 were synthesized at $25^{\circ} \mathrm{C}$ using the neutralization method. These powders, differing by stoichiometry and particle morphology, were compacted in similar conditions. For a similar morphology of particles, compacts of the non-stoichiometric powders have better cohesion than those of the stoichiometric hydroxyapatite $\left(\mathrm{Ca}_{10}\left(\mathrm{PO}_{4}\right)_{6}(\mathrm{OH})_{2}: \mathrm{Ca} / \mathrm{P}=1.67\right)$. The lacunar structure, with deficiency of calcium $\left(\mathrm{Ca}_{10-x}\left(\mathrm{HPO}_{4}\right)_{x}\left(\mathrm{PO}_{4}\right)_{6-x}(\mathrm{OH})_{2-x}: 1.5<\mathrm{Ca} / \mathrm{P}<1.67\right)$, seems to favour the densification process and cohesion between particles during the compaction. The better tensile strength $(0.79 \mathrm{MPa})$ was obtained for the powder with the lowest atomic ratio $(\mathrm{Ca} / \mathrm{P}=1.5, x=1)$. The apatite powder $(\mathrm{Ca} / \mathrm{P}=1.78)$, which has a smooth and porous structure, presented the best transmission load ratio (95.5\%), the lowest die-wall friction ( $\mu=0.1$ ) and the highest strength (3.12 MPa). These results show the importance of chemical composition and morphological properties of synthesized particles in the development of better hydroxyapatite powders for the compaction process.
\end{abstract}

Keywords:

Hydroxyapatite powders

Die-compaction

Mechanical properties

\section{Introduction}

Biomaterials synthesized from calcium phosphates such as hydroxyapatite (HAP) $\mathrm{Ca}_{10}\left(\mathrm{PO}_{4}\right)_{6}(\mathrm{OH})_{2}$, are frequently used as substitutes for the treatment of pathologies in dental surgery. These biomaterials present a good biocompatibility and an excellent bioactivity [1,2]. Calcium phosphates are prepared in different forms: powder, granule or block. For implants with a shape adapted to the bone defect, the powders are compacted in shaped die. To increase the density of the piece, a sintering operation follows the cold compaction. However, the inherent problems of the calcium phosphate, especially hydroxyapaptite, are the poor mechanical properties of the resulting compact [3]. The mechanical properties of this material are largely dependent on their micro-structural features, such as micro-structural defects $[4,5]$ and sintered density. The first important step in producing dense materials is the preparation of a fine powder with particle properties favourable to the compaction. Recently, various studies on the preparation of apatites with different stoichiometry and morphology have been carried out. The aim of this study is to bring a better understanding of the relation between the microstructure and the

* Corresponding authors. Hatim is to be contacted at Electrochimie et Biomatériaux Faculté des Sciences, Université Chouaib Doukkali. B.P. 20, El Jadida, Morocco. Tel.: +212 23372852. Michrafy, RAPSODEE, UMR 2392, Ecole des Mines d'Albi, campus Jarlard 81013 Albi cedex 09, France. Tel.: +33 56349 3162; fax: +33 563493025

E-mail addresses: hatim.z@mailcity.com (Z. Hatim), michrafy@enstimac.fr (A. Michrafy). aptitude of powders to cold compaction. For this purpose, apatitic calcium phosphate powders with different particles properties, were synthesized by the neutralization method (1).

$10 \mathrm{Ca}(\mathrm{OH})_{2}+6 \mathrm{H}_{3} \mathrm{PO}_{4} \rightarrow \mathrm{Ca}_{10}\left(\mathrm{PO}_{4}\right)_{6}(\mathrm{OH})_{2}+18 \mathrm{H}_{2} \mathrm{O}$

The reactants do not contain counter ions that could replace the apatitic sites and influence the aptitude to compression of the powders. As raw material we used ortho-phosphoric acid (produced in Morocco by EMAPHOS - Euro-Maroc-PHOSphore) with controlled chemical composition, and calcium carbonate used in the production of pharmaceutical drugs. We examined the influencing parameters such as stoichiometry, granule morphology and surface properties on the aptitude of apatitic structure powders to compaction.

\section{Materials and methods}

\subsection{Powder synthesis}

The synthesis was carried out by reaction between the calcium hydroxide and the ortho-phosphoric acid. In the first stage, calcium oxide is dispersed under agitation in double distilled water. The calcium oxide is prepared by calcination of $\mathrm{CaCO}_{3}$ (Merck 99\%) at $900{ }^{\circ} \mathrm{C}$ for a period of $24 \mathrm{~h}$. The acid solution is made from orthophosphoric acid (EMAPHOS 85\%) and added to the suspension under mechanical agitation. The reaction is carried out at $25^{\circ} \mathrm{C}$ and $\mathrm{pH}=5.5$ to 9 . The precipitate obtained is filtered and dried at $105^{\circ} \mathrm{C}$ for $24 \mathrm{~h}$. Five apatitic powders were prepared with atomic ratio $\mathrm{Ca} / \mathrm{P}$ between 
Table 1

Characteristics of synthesis materials

\begin{tabular}{lllll}
\hline Materials & $\begin{array}{l}\mathrm{Ca} / \mathrm{P} \text { molar ratio } \\
( \pm 0.005)\end{array}$ & $\begin{array}{l}\text { Mean particle } \\
\text { size }(\mu \mathrm{m})\end{array}$ & $\begin{array}{l}\text { True density } \\
\mathrm{g} / \mathrm{cm}^{3}\end{array}$ & $\begin{array}{l}\text { Bulk density } \\
\mathrm{g} / \mathrm{cm}^{3}\end{array}$ \\
\hline HAP 1 & 1.512 & $91.2 \pm 0.1$ & $2.6806 \pm 0.020$ & 0.403 \\
HAP 2 & 1.622 & $81.9 \pm 1.0$ & $2.9234 \pm 0.019$ & 0.412 \\
HAP 3 & 1.630 & $89.4 \pm 0.8$ & $2.9794 \pm 0.003$ & 0.403 \\
HAP4 & 1.676 & $90 \pm 1.0$ & - & - \\
HAP 5 & 1.720 & $76.4 \pm 1.2$ & $2.9103 \pm 0.022$ & 0.411 \\
HAP 6 & 1.781 & $15.2 \pm 0.5$ & $3.0014 \pm 0.018$ & 0.202 \\
\hline
\end{tabular}

1.5 and 1.8. The sample was referred as HAP1, HAP2, HAP3, HAP4 and HAP5. Also, Carbonate-apatitic powder was synthesized in the same condition at $\mathrm{pH}=8$, in presence of ions carbonates. The sample was referred as HAP6.

\subsection{Characterization of powders}

The physical and chemical analyses were carried out on the dried precipitate and the powder calcined at $900{ }^{\circ} \mathrm{C}$ for $24 \mathrm{~h}$. The phases formed were identified by the atomic ratios $\mathrm{Ca} / \mathrm{P}$, determined by infrared spectroscopy (Perkin-Elmer FTIR 1600), and by X-ray diffraction (Counter D500, $\lambda_{\mathrm{Cu}}=1.5408 \AA$ ). The software used for data processing of X-ray diffraction was DIFFRACT/AT. The ratio of calcium and phosphorus was determined by an atomic emission spectrophotometer with argon plasma and inductive coupling (ICP-AES) using the wavelengths characteristic of calcium $\lambda=317.933 \mathrm{~nm}$ and of phosphorus $\lambda=213.618 \mathrm{~nm}$. Laser diffraction was used to analyse particle size on the Mastersizer 2000 (from Malvern Instruments Ltd.). The true density $\left(\left(\rho_{\text {true }} \mathrm{g} / \mathrm{cm}^{3}\right)\right.$ was determined using a helium pycnometer (Accupyc 1330, Micrometrics Instruments). Morphologies of granules were observed using a Scanning Electron Microscope.

\subsection{Powder compaction}

The synthesised materials (HAP sample 1 to 5 ) were ground in a mortar. The powder obtained was sieved to obtain a particle size ranging from 40 to $125 \mu \mathrm{m}$. The HAP6 sample was not ground as its particle size was lower than $40 \mu \mathrm{m}$. Tablets of $0.4 \pm 0.01 \mathrm{~g}$ of powder were prepared by compaction using a reciprocating press (Frogerais OA). The upper and lower punchs were instrumented with load and displacement sensors. The cylindrical die of $11.28 \mathrm{~mm}$ in diameter was instrumented with a gauge measuring the radial stress during the compaction cycle. The gauge was positioned at $1.5 \mathrm{~mm}$ from the position of the lower punch. Thus, at the end of the compaction, the tablet height was between 3 and $3.5 \mathrm{~mm}$ and thus, the gauge measures the radial stress at the middle of the tablet. As the radial stress depends on the tablet height, the measured value will be considered as the mean along the height. The powder was poured into the die and compacted at different pressures. To define the range of admissible pressures where the samples could be compacted (and compared), two pressures were characterized for each sample: the lowest pressure needed to form a tablet easy to handle and the highest pressure after which systematic capping happened. The lower pressures were estimated in the range 30-40 MPa and the maximum pressures were in the range 90-110 MPa. Once the tablet ejected, its mass was measured with an electronic balance (CP 224S Sartorius Germany) and its dimensions were measured with digital micrometer (Mitutoyo). The apparent and relative densities were recorded. The diametrical crushing load was also measured with the Erweka TBH 30 apparatus.

\subsection{Characterization of the compaction}

In the compaction process, two ratios are classically used to compare and analyze the behavior of powders. The transmission ratio (2), defined as the ratio of the transmitted pressure $\sigma_{\mathrm{b}}$ to the bottom punch over the applied pressure $\sigma_{\mathrm{u}}$ on the upper punch. This ratio measures the capacity of powder to transmit the load from the top to the bottom of the powder bed. The transfer ratio (3) represents the ratio of the radial pressure $\sigma_{\mathrm{r}}$ over the applied pressure $\sigma_{\mathrm{u}}[6]$.

$$
\begin{aligned}
& \operatorname{tr}=\sigma_{\mathrm{b}} / \sigma_{\mathrm{u}} \\
& \alpha=\sigma_{\mathrm{r}} / \sigma_{\mathrm{u}}
\end{aligned}
$$

Due to the load transfer to the radial direction, a part of the energy of the compaction is stored as elastic energy in the die. During the unloading, a part of this elastic energy is restored to the tablet and contributes to the tension of the tablet. During the compaction, the die wall friction is the dominant property that controls the density

\section{(a) $200 \mu \mathrm{m}$}

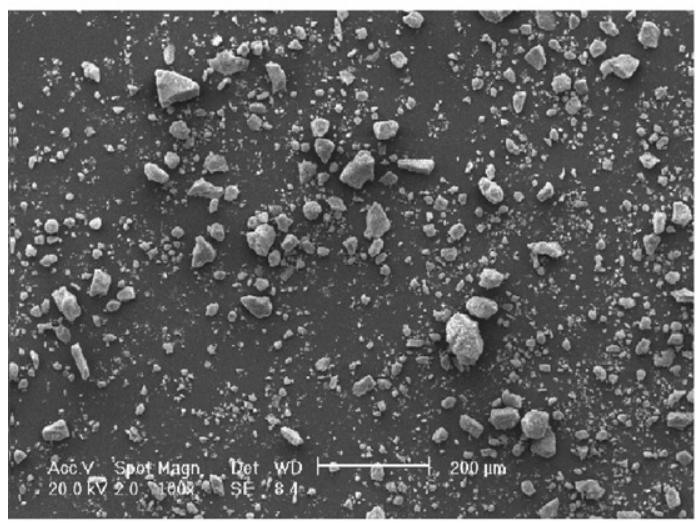

(b) $20 \mu \mathrm{m}$

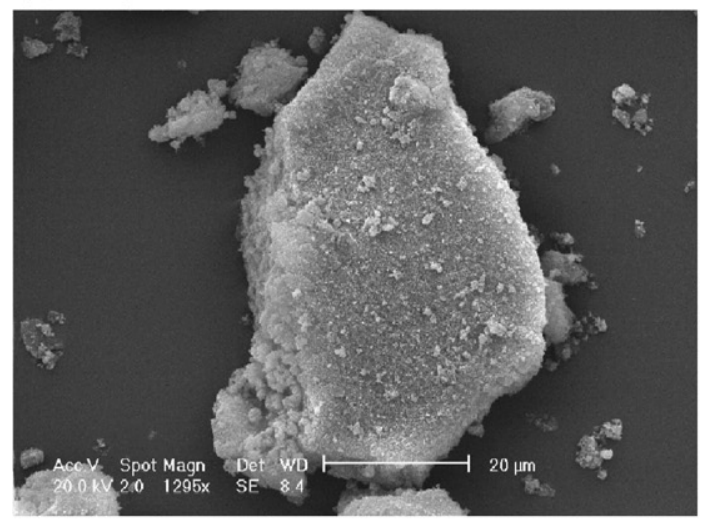

(c) $\underline{\mu \mathrm{m}}$

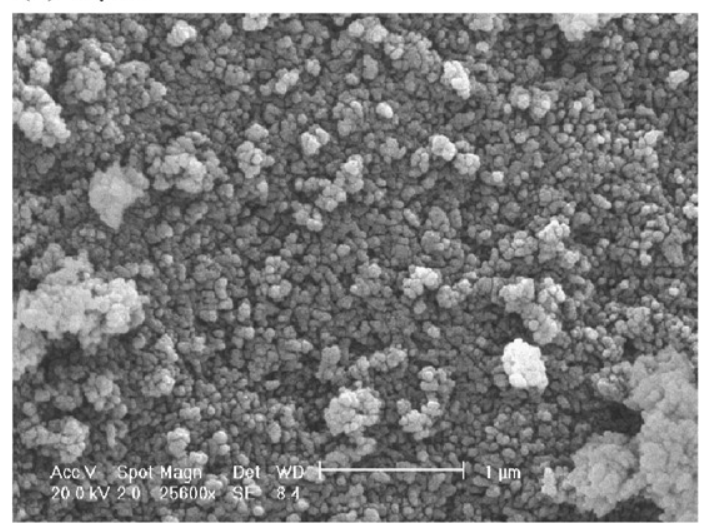

Fig. 1. SEM micrographs of the synthesised powder HAP1 $(\mathrm{Ca} / \mathrm{P}=1.512)$. (a) Polydispersed population, (b) granule of the powder, (c) typically surface morphology. 


\section{(d) $\underline{200 \mu \mathrm{m}}$}

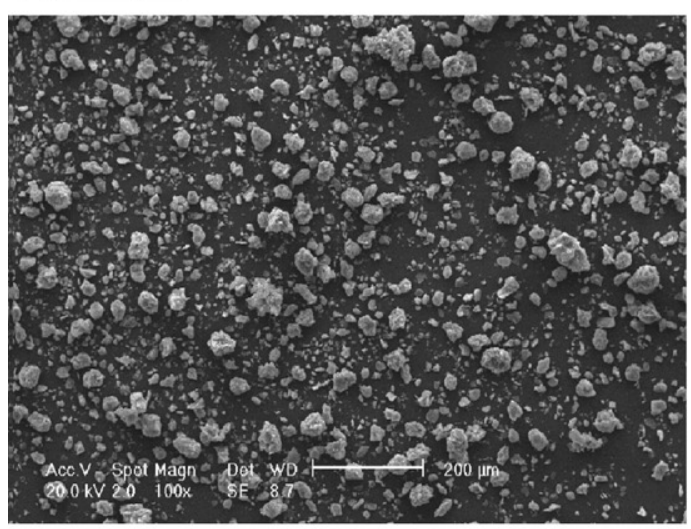

(e) $\underline{20 \mu m}$

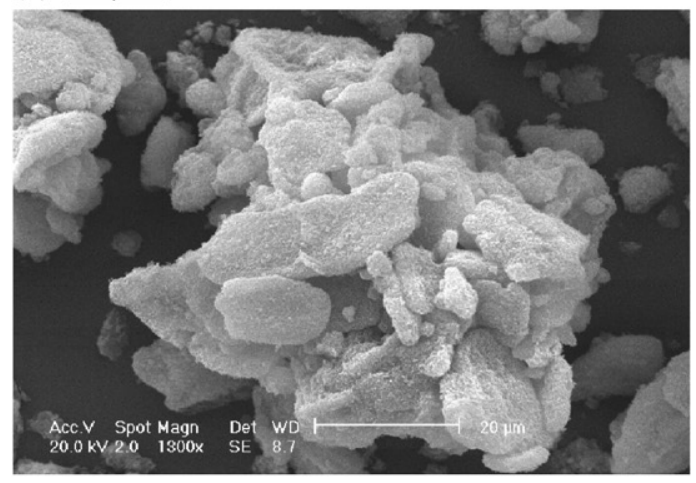

(f) $\underline{1 \mu \mathrm{m}}$

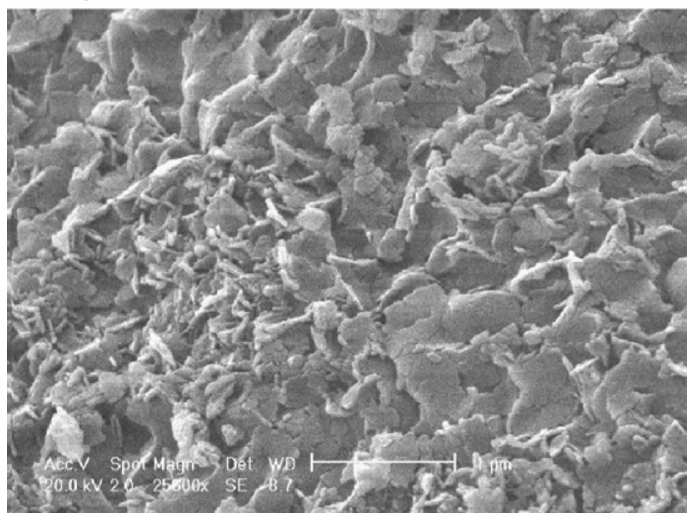

Fig. 2. SEM micrographs of the synthesised powder HAP6 $\mathrm{Ca} / \mathrm{P}=1.781$. (d) Polydispersed population, (e) granule of the powder, (f) typically surface morphology.

distribution and the load transmission over the powder bed. Assuming the Coulomb friction and adopting the 'method of differential slices' [7], the die-wall friction may be obtained:

$\mu=\ln \left(\sigma_{\mathrm{b}} / \sigma_{\mathrm{u}}\right) /(-4 \alpha H / D)$

where $H / D$ named the aspect ratio, is the ratio of the height over the diameter of the tablet at the end of the compaction. The tensile strength $\left(\sigma_{\mathrm{t}}\right)$ of the tablet was calculated from the diametrical crushing load $F$ as:

$\sigma_{\mathrm{t}}=2 F /(\pi D H)$

To analyze the aptitude of powders to compaction and to establish correlations with stoichiometric ratio and particles morphologies, a pressure of $70 \mathrm{MPa}$ (value in the admissible pressures range of all the samples) was used.

\section{Results}

\subsection{Population, morphology, composition of granules}

Chemical analyses of the calcium and phosphorus elements, carried out by ICP, enabled us to calculate the atomic molar ratio $\mathrm{Ca} / \mathrm{P}$ of all the samples. The results are given in Table 1.

Scanning Electron Microscopy images of the samples showed two structure groups (Figs. 1 and 2). Micrographs of the powder HAP1 (HAP2, HAP3, HAP4 and HAP5 were similar to HAP1) showed poly-dispersed population (a), irregular granule shape, composed of small spherical particle agglomerates (b), and a rough surface (c). The typical agglomerate size of these powders was $91.2 \pm 1.0 \mu \mathrm{m}$ (for the other powders, values are given in the Table 1). Indeed, micrographs of the powder HAP6 (Fig. 2) showed a mono-dispersed population (d), spherical particles in an assembly of agglomerate layers (e) and presented a smooth surface (f). The means agglomerates size was $15.2 \pm 0.5 \mu \mathrm{m}$. Furthermore, there is a more important intra-granular porosity comparative to powders HAP1... HAP5.

Characterization the synthesised powders by infrared spectroscopy (Fig. 3) showed for all the samples the characteristic bands of phosphate groups at $470,560-600,960,1030-1120 \mathrm{~cm}^{-1}$. The bands at 630 and $3560 \mathrm{~cm}^{-1}$ were characteristic of groups $\mathrm{OH}$. A band at $875 \mathrm{~cm}^{-1}$ could be attributed to $\mathrm{HPO}_{4}$ which is characteristic of calcium deficient hydroxyapatite (samples HAP1, 2 and 3). The bands at $1640 \mathrm{~cm}^{-1}$ and the bands at $875.4,1420$ and $1450 \mathrm{~cm}^{-1}$ indicate respectively the presence of traces of water and carbonate groups. The sample 6 clearly showed some $\mathrm{CO}^{3-}$ derived bands observed at $870 \mathrm{~cm}^{-1}$ and around $1420-1480 \mathrm{~cm}^{-1}$ characteristic of carbonate apatite.

The XRD patterns of the precipitated powders are shown in Fig. 4. All powders dried at $105{ }^{\circ} \mathrm{C}$ had the same apatitic structure as hydroxyapatite and no other crystalline phase was detected (Fig. 4b). During the calcination at $900{ }^{\circ} \mathrm{C}$ of the samples 1 to 5 (Fig. 4a), a calcium excess $(\mathrm{Ca} / \mathrm{P}>1.67$ for sample 5$)$ resulted in the presence of
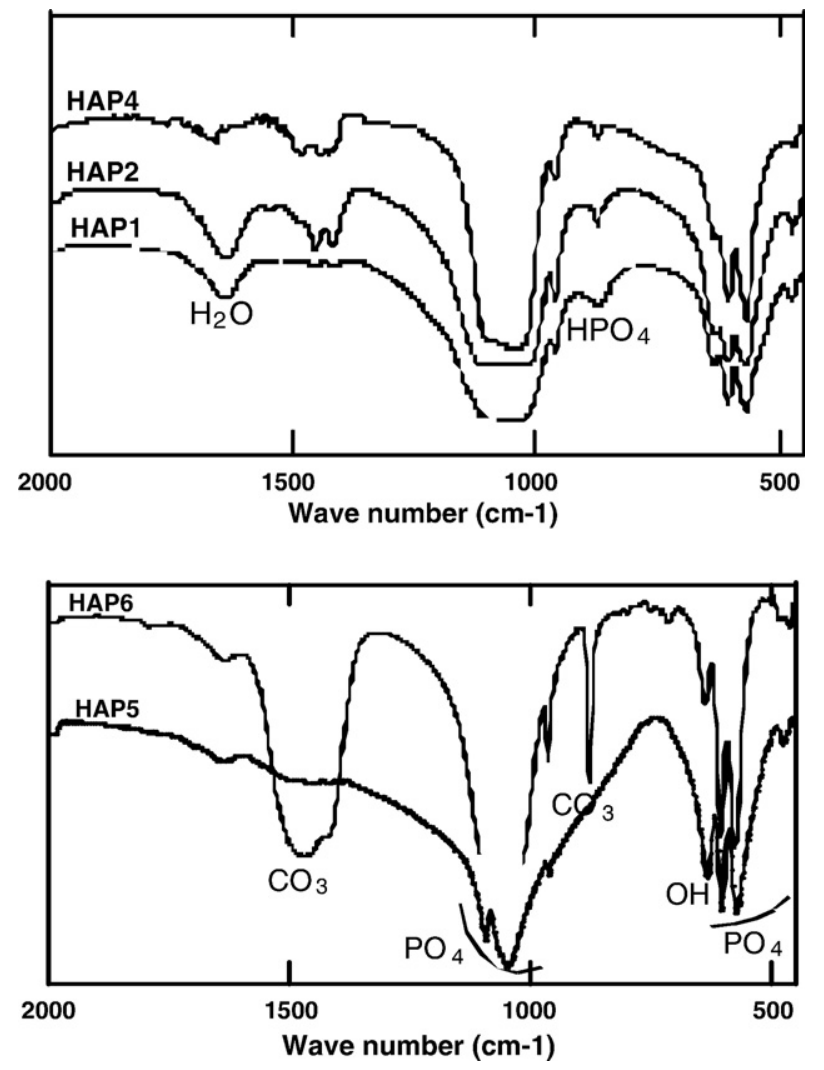

Fig. 3. IR spectrum of synthesised powders (HAP1, HAP2, HAP4, HAP5 and HAP6). 
(a)
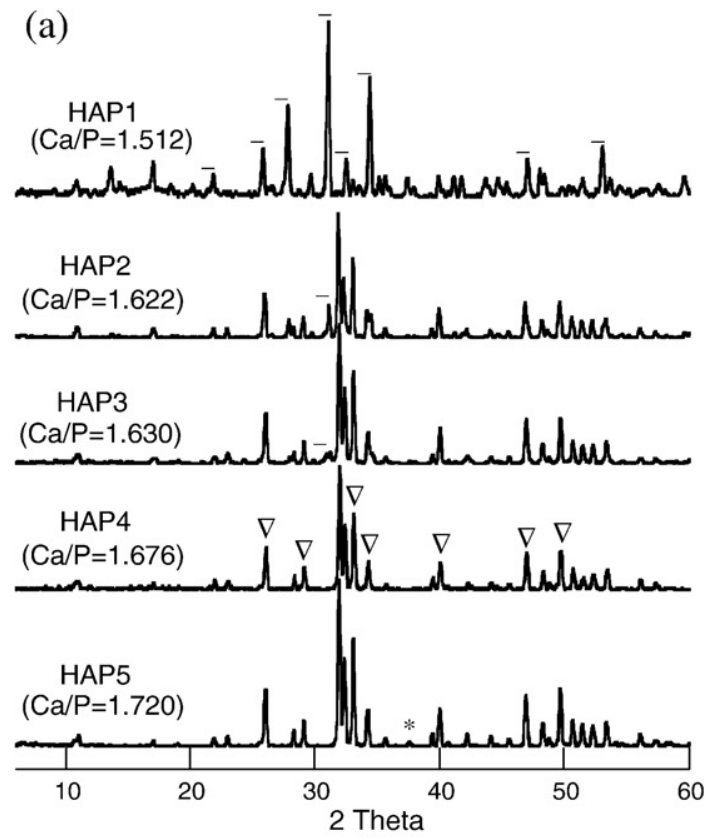

(b)

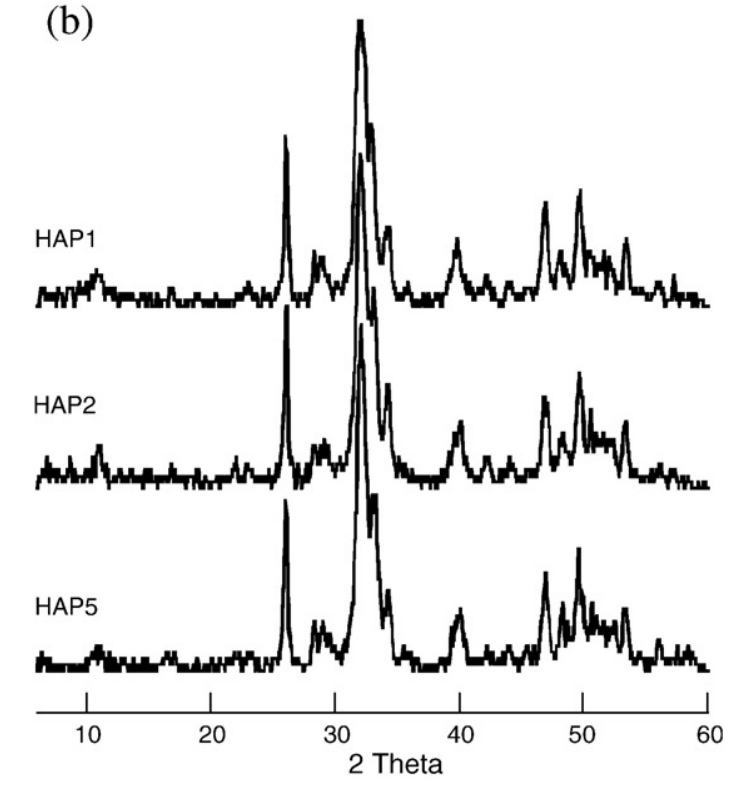

Fig. 4. XRD pattern of calcined powder (a) and synthesized powder (b). $-\beta-\mathrm{Ca}_{3}\left(\mathrm{PO}_{4}\right)_{2}$, $\Delta \mathrm{Ca}_{10}\left(\mathrm{PO}_{4}\right)_{6}(\mathrm{OH})_{2}, * \mathrm{Ca}(\mathrm{OH})_{2}$

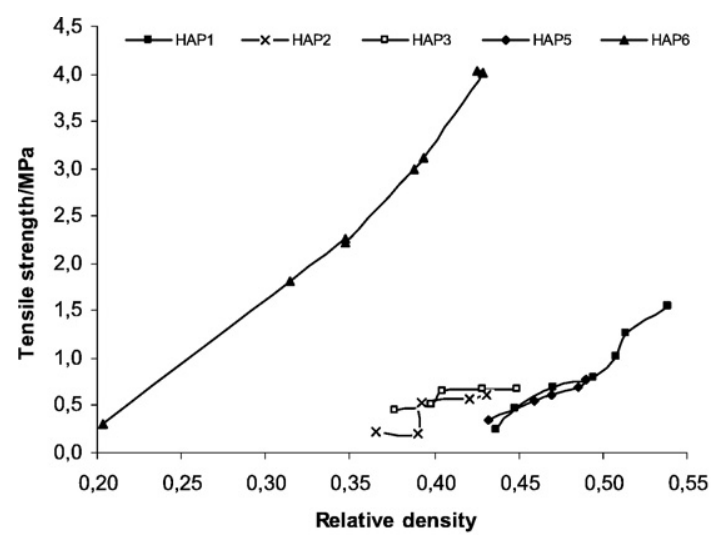

Fig. 5. Tensile strength versus relative density of tablets prepared from HAP powders.

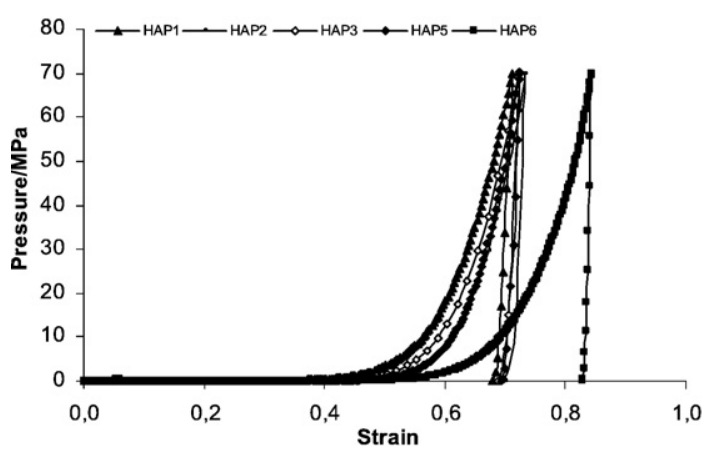

Fig. 6. Axial pressure versus axial strain during die-compaction of HAP powders.

calcium oxide as the secondary phase, whereas a phosphorus excess $(\mathrm{Ca} / \mathrm{P}<1.67$ for samples 1,2 , and 3$)$ results in the presence of tricalcium phosphate type ( $\beta-\mathrm{TCP})[8]$. The initial apatite dissociated into a mixture of HAP and $\beta$-TCP according to the overall reaction:

$\mathrm{Ca}_{10-x}\left(\mathrm{HPO}_{4}\right)_{x}(\mathrm{PO} 4)_{6-x}(\mathrm{OH})_{2-x} \rightarrow(1-x) \mathrm{Ca}_{10}\left(\mathrm{PO}_{4}\right)_{6}(\mathrm{OH})_{2}+3 x \mathrm{Ca}_{3}\left(\mathrm{PO}_{4}\right)_{2}$ $+x \mathrm{H}_{2} \mathrm{O}$, With $0 \leq x \leq 1$

The XRD patterns of the sample HAP1 with $x \approx 1$ highlights the structure of pure tricalcic phosphate $\beta-\mathrm{Ca}_{3}\left(\mathrm{PO}_{4}\right)_{2}$. This indicates that the initial powder has the formula: $\mathrm{Ca}_{9}\left(\mathrm{HPO}_{4}\right)\left(\mathrm{PO}_{4}\right)_{5} \mathrm{OH}$.

The XRD patterns of the sample 4 with $x=0$ (Fig. 4) highlights the structure of the stoichiometric hydroxyapatite $\left(\mathrm{Ca}_{10}\left(\mathrm{PO}_{4}\right)_{6}(\mathrm{OH})_{2}\right.$.

\subsection{Aptitude of powders to the die-compaction}

The compressive behaviour of the powders of apatitic structure with different molar fractions and two different morphologies were analysed prior to the aptitude to compression. The admissible pressures of the studied powders were estimated between 30 and $110 \mathrm{MPa}$. The tensile strength versus relative density of powders in this pressure range, is plotted in Fig. 5. The results concerning stoichiometric apatite (HAP4) are not presented because of the low cohesivity of the powder. For samples HAP1 $(\mathrm{Ca} / \mathrm{P}=1.512)$ and HAP6 $(\mathrm{Ca} / \mathrm{P}=1.781)$, the tensile strength increases with pressure. However, strength of powder HAP3 $(\mathrm{Ca} / \mathrm{P}=1.630)$ and HAP5 $(\mathrm{Ca} / \mathrm{P}=1.720)$ underwent little changes and remains weak.

The axial stress versus the axial strain of the compaction at $70 \mathrm{MPa}$, is plotted in Fig. 6. Curves showed the better compressibility for the powder HAP6 (the axial strain of the bed at $70 \mathrm{MPa}$ was higher $84 \%$ ) whereas the bed of powders HAP1, 2, 3 and 5 was deformed up to $70 \%$. The aptitude of the powders to compaction was characterised by the transmission ratio (Eq. (1)), the transfer ratio (Eq. (2)) and the die-wall friction (Eq. (3)) calculated from measurements at the end of the compaction. Values of these ratios are reported in the Table 2. The transmission ratio was found to be in the range 71-95.5\%, the powder HAP6 gave the highest value (95.5\%), followed by the powders HAP1, HAP2 and HAP3 (90\%; 90\%; 88\%). The lowest value of the transmission was obtained with the powder HAP5 (71\%). The transfer ratio was between 41.8 and 45.8. The powders HAP1, 5 and 6 show similar

Table 2

Mechanical properties of compact

\begin{tabular}{llllll}
\hline Material & $\begin{array}{l}\text { Relative } \\
\text { density }\end{array}$ & $\begin{array}{l}\text { Transmission } \\
\text { ratio }\end{array}$ & $\begin{array}{l}\text { Transfer } \\
\text { ratio }\end{array}$ & $\begin{array}{l}\text { Die-wall } \\
\text { friction }\end{array}$ & $\begin{array}{l}\text { Tensile strength } \\
\text { (MPa) }\end{array}$ \\
\hline HAP 1 & 0.4905 & 90 & 41.8 & 0.22 & $0.79 \pm 0.02$ \\
HAP 2 & 0.4307 & 90 & 45.3 & 0.20 & $0.61 \pm 0.03$ \\
HAP 3 & 0.4489 & 88 & 45.8 & 0.24 & $0.67 \pm 0.08$ \\
HAP 5 & 0.4599 & 71 & 43 & 0.69 & $0.55 \pm 0.03$ \\
HAP 6 & 0.3936 & 95.5 & 42 & 0.1 & $3.12 \pm 0.08$ \\
\hline
\end{tabular}


values 41.8, 43 and 42, indeed, the transfer ratio of the powders HAP2 and HAP3 takes 45.3 and 45.8. The ratio characterizing the die-wall friction gave complementary information on the behaviour of the powders. This ratio is 0.1 for the powder HAP6, and 0.2 to 0.24 for the powders HAP1, HAP2 and HAP3 and 0.69 for the powder HAP5.

In the last column of the Table 2, the tensile strength of the powders compacted at $70 \mathrm{MPa}$ are given and the values showed the highest value for the powders HAP6 (3.12 MPa) and the lowest value for the powder HAP 5 (0.55 MPa).

\section{Discussion}

\subsection{Stoichiometry and morphology of apatitic granules}

Various physicochemical analyses give the compositions and the morphologies of all the powders prepared. All the powders have a badly crystallized apatitic structure. The sample HAP4 of atomic ratio $\mathrm{Ca} /$ $\mathrm{P}=1.676$ corresponds to a stoichiometric hydroxyapatite $\left(\mathrm{Ca}_{10}\left(\mathrm{PO}_{4}\right)_{6}\right.$ $\left.(\mathrm{OH})_{2}\right)$.

The samples HAP1, 2 and 3 are Ca-deficient apatites with substitutions of grouping $\mathrm{PO}_{4}$ by $\mathrm{HPO}_{4}$ according to the formula: $\left(\mathrm{Ca}_{10-x}\left(\mathrm{HPO}_{4}\right)_{x}\left(\mathrm{PO}_{4}\right)_{6-x}(\mathrm{OH})_{2-x}\right) x$ takes the values 0.268 and 0.220 successively for the powders HAP2 and HAP3. The powder 1 of atomic ratio $\mathrm{Ca} / \mathrm{P}=1.512(x \approx 1)$ corresponds to tricalcium phosphate of apatitic structure $\left(\mathrm{Ca}_{9}\left(\mathrm{HPO}_{4}\right)\left(\mathrm{PO}_{4}\right)_{5} \mathrm{OH}\right)$. Sample 5 of atomic ratio $\mathrm{Ca} / \mathrm{P}=1.720$ is a hydroxyapatite with a slight excess in calcium. The simples ( 1 to 5 ) showed similar shape and particle size. It appears to have a non regular shape and a poly dispersed paricle size. Also, low intragranular porosities may be noted. The effect of stoichiometry on the morphology of these powders was negligible. Measurements of the specific surface and true density show little differences between the powders.

The sample HAP6 is an apatite carbonate where ions $\mathrm{PO}_{4}$ are substituted by carbonate ions. This powder shows a rounded shape and near regular size. Moreover, observation of granule shows a smooth surface of the layers and an important intra-granular porosity due to the geometrical structure of the granule. The bulk density of the powder HAP6 was twice the bulk density of the powders HAP1 to 5 . This was mainly due to the porous structure of the granules of the powder HAP6.

\subsection{Effect of stoichiometry and morphology on the aptitude to the compaction}

For the powders HAP1, 2 and 3, the transmission ratio and the diewall friction were similar for the compaction up to $70 \mathrm{MPa}$. The resulting tensile strength $(0.61-0.79 \mathrm{MPa})$ shows the best tensile value for the powder HAP1 $(0.79 \mathrm{MPa})$. The lowest value of the transfer ratio for this powder $(\alpha=41.8)$ means that the elastic energy stored in the die during the compaction was lower than the case of compaction of the powders 2 and 3 ( $\alpha=45.3-45.8$ ). During the decompression step, the elastic energy restored to the tablet was thus lower for the powder 1. This favours tension in the tablet and may reduce the tensile strength. The lower value of the tensile strength of the powder HAP5 could be explained by the high value of the die-wall friction $(\mu=0.69)$ and the bad transmission ratio $(\operatorname{tr}=71 \%)$. In these conditions, the top of the tablet was quite compacted, whereas, the bottom was poorly compressed. These results indicate that stoichiometry and nonstoichiometry plays an important role for the aptitude to the compaction. The substitution of ions $\mathrm{PO}_{4}$ by ions hydrogeno- phosphate $\left(\mathrm{HPO}_{4}\right)$ in the network leads to an apatite that lacks calcium. Electric neutrality is then ensured by reduction in the cation load, by substitution of $\mathrm{Ca}$, and then by the creation of vacancy according to the formula $\left(\mathrm{Ca}_{10-x} \square_{x}\left(\mathrm{HPO}_{4}\right)_{x}\left(\mathrm{PO}_{4}\right)_{6-x}(\mathrm{OH})_{2-x}\right.$ where $\square$ represents ionic vacancies) $0 \leq x \leq 1$. The amount of hydrogenophosphate ions and the vacant sites increase with the reduction in the $\mathrm{Ca} / \mathrm{P}$ ratio. Comparatively to the powders $2,3,4$ and 5 , the better tensile strength of the powder $\mathrm{HAP} 1(\mathrm{Ca} / \mathrm{P}=1.521)$ was probably due to the chemical composition where the presence of voids and molecular groups $\mathrm{HPO}_{4}$ were important. This structure seems to support the connection between particles during the compaction. The sample 5 with excess in Ca presented the highest value of die-wall friction and the sample 4 with $\mathrm{Ca} / \mathrm{P}=1.676$ presents a bad cohesion between the particles. The overall results indicate that the good aptitude with the compaction decreases, following the sequence of $\mathrm{Ca} / \mathrm{P}$ : $1.512>1.622>1.630>1.720>1.676$.

The low value of the die-wall friction $(\mu=0.1)$ of the powder HAP6 $(\mathrm{Ca} / \mathrm{P}=1.781)$ may be attributed to the smooth porous structure of the granules surface. The brittle and porous structures of the granules act in favour of the compressibility. In fact, the better transmission ratio (95.5\%) and the low die-wall friction favours the homogeneous density and hence the highest tensile strength. It could be concluded, that the morphology in its smoothness and the porous structures of the granule surface were the most important factor for the aptitude to the compaction than the non stoichiometry.

The overall results show the importance of chemical composition and morphological properties of synthesized particles in the development of better hydroxyapatite powders for the compaction process.

\section{Conclusion}

In this study, we have examined parameters such as stoichiometry, granule morphology and surface properties which influence the aptitude to compaction of apatitic structure powders. The samples were synthesized at low temperature using the neutralization method and compacted in similar conditions. The results indicate that stoichiometry plays an important role for the aptitude to the compaction. During compression, the lacunar structure of Ca-deficient apatites seems to support the cohesion between particles. But the morphology in its smoothness and the porous structures of the granule surface were the most important factors for the aptitude to the compaction that leads to the homogeneous density and hence the highest tensile strength.

\section{References}

[1] R.Z. LeGeros, Biological and synthetic apatites, in: P.W. Brown, B. Constanz (Eds.) Hydroxyapatite and related materials, CRC Press, Boca Raton, FL, 1994, pp. 3-28.

[2] O. Gauthier, J.-M. Bouler, E. Aguado, R.Z. LeGeros, P. Pilet, G. Daculsi, Elaboration conditions influence physicochemical properties an in vivo bioactivity of macroporous biphasic calcium phosphate ceramics, J. Mater. Med. 10 (1999) 199-204.

[3] F.N. Oktar, G. Göller, Sintering effects on mechanical properties of glass-reinforced hydroxyapatite composites, Ceram. Int. 28 (2002) 617-621.

[4] M. Bohner, Physical and chemical aspects of calcium phosphates used in spinal surgery, Eur. Spin J. 10 (2001) 114-121.

[5] G. Gregori, H.-J. Kleebe, H. Mayr, G. Ziegler, EELS, characterisation of $\beta$-tricalcium phosphate and hydroxyapatite, J. Eur. Ceram. 26 (2005) 1473-1479.

[6] A. Michrafy, M.S. Kadiri, J.A. Dodds, Wall friction and its effects on the density distribution in the compaction of pharmaceutical excipients, Trans IchemE 81 (2003) 946-952 Part A

[7] R.M. Nedderman, Statics and kinematics of Granular Materials, Cambridge University Press, 1992.

[8] AFNOR, NF S 94-066, AFNOR Paris (1998). 